\title{
Energy use pattern of rice production in Eastern Agro- Climatic Zone of Haryana
}

\author{
Parmod Sharma, Yadvika*, Kanishk Verma and Y. K. Yadav \\ Department of Renewable and Bio-Energy Engineering, C.C.S. Haryana Agricultural University, \\ Hisar (Haryana) India (Email: sharma.parmod2008@gmail.com)
}

\begin{abstract}
Paddy covers approximately half of the total area covered by cereal crops in India. Rice crop cultivated under watery condition either by storing canal water or pumping water or both, by utilizing a lot of electric/diesel energy especially when pumping is carried out. The amount of rice production is a direct function of energy inputs and outputs. The aim of this study was to examine the operation-wise and source-wise energy consumption pattern in rice crop production in eastern agro-climatic zone of Haryana. The data was collected through a questionnaire by face to face interviews. The amount of energy consumed in seedlings, land development, land preparation, transplanting, irrigation, weeding, fertilizer, harvesting and threshing and transportation were calculated for rice crop cultivation. The energy inputs in seed, human, diesel, electricity, machinery and fertilizer were taken into consideration to determine the source wise energy that was used in rice production. The average energy input of large farmers (LF), marginal farmers (MF) and small farmers (SF) was observed to be $43693.82,42557.21$ and $41915.70 \mathrm{MJ} /$ ha, respectively while output energy was 146660, 144528 and $136596 \mathrm{MJ} / \mathrm{ha}$, respectively. Specific energy of large, medium and small category framers were $8.24,8.12$, and $8.50 \mathrm{MJ} / \mathrm{ha}$, respectively. The result revealed that irrigation, fertilizer and electricity consumed the bulk of energy. The result also showed that energy ratio, energy productivity and net energy gain of all category farmers were lie within the range of 3.26 to $3.40,0.09$ to $0.12 \mathrm{~kg} / \mathrm{MJ}$ and 94680.30 to $102966.18 \mathrm{MJ} / \mathrm{ha}$, respectively. Yield rice grain per hectare of large, medium and small category framers were 53.00, 52.40 and 49.30 quintal, respectively.
\end{abstract}

Key Words : Rice, Energy Input, Energy output, Specific energy

View Point Article : Sharma, Parmod, Yadvika, Verma, Kanishk and Yadav, Y.K. (2019). Energy use pattern of rice production in Eastern Agro-Climatic Zone of Haryana. Internat.J.agric.Sci., 15 (2) : 283-287, DOI:10.15740/HAS/IJAS/15.2/283-287. Copyright@ 2019: Hind Agri-Horticultural Society.

Article History : Received : 07.04.2019; Revised : 11.05.2019; Accepted : 20.05.2019

*Author for correspondence: 